\title{
EFFECT OF CHITOSAN ADDITION DURING PAPER-MAKING ON AGEING STABILITY OF DOCUMENT PAPER
}

\author{
DIMITRINA TODOROVA and VESKA LASHEVA
}

\author{
Department of Pulp, Paper and Printing Art, University of Chemical Technology and Metallurgy, \\ $8 \mathrm{Kl}$. Ohridski Blvd., 1756 Sofia, Bulgaria \\ ๑Corresponding author: D. Todorova, todorova.dimitrina@uctm.edu
}

Received January 14, 2021

\begin{abstract}
The aim of the present work has been to study the influence of chitosan addition into the composition of paper intended for documents on its ageing stability, with a view of enhancing the resistance of paper strength and optical properties over time. The chitosan solution was added during the formation of the paper sheets in various amounts: $0.2 \%, 1 \%$ and 2\% o.d.f. Paper samples of different fibrous compositions were prepared from bleached sulphate softwood pulp (BSWP) and bleached sulphate hardwood pulp (BHWP) in the following ratios: 50\% BSWP:50\% BHWP, 80\% BSWP:20\% BHWP, 100\% BSWP and 100\% BHWP. Then, paper samples were subjected to accelerated thermal ageing for 24 hours at $105^{\circ} \mathrm{C}$. It was found that the use of chitosan as additive in the composition of bleached cellulose paper samples led to improved strength and hygroscopic properties. The study showed that chitosan could be used in the production of kraft document papers comprising aluminium sulphate, as the presence of aluminium sulphate had no negative effect on the action of the biopolymer. Regarding the complex evaluation of the properties of the obtained papers, it could be summarized that, for the studied fibrous compositions, the optimum amount of the additive was $1 \%$ chitosan for a fibrous composition of $50 \%$ bleached softwood pulp and $50 \%$ bleached hardwood cellulose. Therefore, preparing document paper with the addition of chitosan is a convenient procedure to enhance a number of paper properties, even after the ageing process.
\end{abstract}

Keywords: chitosan, ageing, paper, strength, hygroscopic properties

\section{INTRODUCTION}

In the conservation of archives, the main objective is to provide conditions to protect documents and artefacts from biological attack, namely, from insects and mould, as well as control environmental factors, such as temperature, relative air humidity and light, which can also affect the degree of ageing stability of materials, especially paper. Paper aging may be caused by mechanical, physical, chemical, photochemical, biochemical and radiochemical factors. Moreover, the wide variety of raw materials used in the production of paper, the papermaking chemistry and technology limit the possibility of comparing the effects of such factors when investigating the aging stability of paper. Therefore, knowledge of the behaviour of paper, particularly the changes in paper strength and optical properties, is of constant interest, in order to preserve cultural heritage, in the form of documents and books.
In terms of chemical aging processes, cellulose and the lignin content remaining in the pulp play crucial roles. It is known that aging alters the hypermolecular properties of paper (hornification) - a partly reversible process, stimulated by beating - and the chemical composition of lignin and cellulose, by fully irreversible deteriorative processes, with a fatal impact on cellulosic matter. Cellulose aging may be induced by acid and enzymatic hydrolysis, chemical and photochemical oxidation, or a combination of reactions. Typically, these processes induce fragility and yellowing of cellulose and lignocellulosic materials. The hydrolytic division of the basic content of paper cellulose is the major cause for its premature decay. During the process, cellulose molecules get depolymerised, and at an advanced stage, cellulose fibres lose their tensile strength. ${ }^{1-4}$ Besides the composition, a crucial factor responsible for the aging behaviour of 
paper is represented by the environmental conditions that the paper or paperboard is exposed to during storage. Technological research has shown that even highly acidic paper, when stored correctly - under constant temperature and relative humidity, in accordance with current archival standards - was highly durable and ageing resistant. ${ }^{4}$

Considering the value of archive documents, they can be rarely sampled for investigating their properties, and since paper aging is a timeconsuming process, for research purposes, paper samples meeting specific parameters are often subjected to artificial aging, which most often involves thermal ageing. In most cases, the thermal aging of paper is caused by oxidation processes, under the influence of oxygen from the air, and hydrolysis, under the influence of moisture, or their combined action. The depth of these changes depends not only on the temperature, but also on the duration of the exposure. The decomposition of cellulose takes place initially in the amorphous parts, and then affects the crystalline ones, while reducing the degree of polymerization. As a result of thermal aging, the content of $\alpha$-cellulose decreases, that of $\beta$-cellulose increases and that of $\gamma$-cellulose is also periodically reduced. ${ }^{1,4-6}$

Durable and age-resistant papers should meet the following important parameters:

- The raw fibre material should consist only of bleached cellulose pulp;

- The pulp should have low content of oxidizable material, indicated by the Kappa value, as well as an alkaline buffer (an alkaline reserve);

- The $\mathrm{pH}$ value of the cold water extract should be between 7.5 and 10 .

Despite the many recent existing works dealing with accelerated aging of paper, there are still knowledge gaps in this field, which require further research. For example, no clear correspondence between artificial and natural aging has been made, and this point is of an outstanding importance to the people working in conservation. ${ }^{4}$ The development of protective packaging for paper and books has also drawn a significant interest. However, further research in this field is necessary.

Bio-based polymers are polymers that can be directly extracted from biomass (polysaccharides, proteins and lipids), those synthesized from bioderived monomers (polylactic acid - PLA or other polyesters), or those produced directly by microorganisms (polyhydroxyalkanoates - PHA, bacterial cellulose, xanthan, pullulan and curdlan). Bio-based polymers are usually used in coatings for paper and cardboard, applied with different coating techniques (solution coating, surface sizing, curtain coating or compression moulding). ${ }^{7-9}$ Out of polysaccharides, the most frequently used are chitosan, starches (rice, wheat, maize, corn and potato), cellulose and alginates. They are nontoxic, widely accepted, obtained from abundant raw materials and available on the market. With great gas, aroma and grease barriers, such coatings have great potential in packaging materials. However, because of their hydrophilic nature, polysaccharides exhibit poor water vapour barrier. $^{7-9}$

Another research direction in paper ageing is to try to introduce bio-based materials, such as chitosan, in the composition of paper to slow down the aging process and achieve more stable strength and whiteness over time. Additives, such as polysaccharides, also enhance the barrier properties of the final product. Another advantage of using polysaccharides, such as chitin and starch, as additives is that they belong to green chemicals and are characterized by their availability, renewability and biodegradability. ${ }^{10}$

Chitosan is a hydrophobic polymer and a cation derived from the elimination of acetyl chitin in alkaline environment (Fig. 1). ${ }^{11}$ Chitin, a linear polysaccharide of $\beta$-(1 $\rightarrow 4)-2$-deoxy-2acetamido-d-glucopyranose, is a major polysaccharide found in crustaceous shells and in the cell walls of fungi. In its chemical structure, chitin is similar to cellulose, but it is different in that it has an acetamide group instead of a hydroxyl group at the $\mathrm{C}-2$ position within the glucose unit.

Chitosan, which is a linear copolymer of $\beta$ $(1,4)$-2-acetoamido-2-deoxy-D-glucopyranose units and $\beta$-(1,4)-2-amino-2-deoxy-Dglucopyranose units, is one of the most widespread natural polysaccharides. It exhibits excellent oxygen-barrier properties due to its high crystallinity and hydrogen bonds between molecular chains. ${ }^{12}$ The presence of $-\mathrm{NH}_{2}$ group transforms it into a polycation in a dilute acidic solution. As a result, the cationic character causes stronger adsorption by electrostatic interactions to the paper pulp, which has an anionic character. ${ }^{13}$

Chitosan interacts with cellulose, which causes improved tensile properties and promotes good printability of paperboard. ${ }^{14}$ Different blends of cellulose and chitosan in papermaking processes have been studied and presented earlier. ${ }^{15-21}$ Laleg 
and Pikulik reported that chitosan additives increased the strength of wet paper towels, disposable diapers, and grocery bags. ${ }^{15} \mathrm{Li}$ et al. stated that chitosan was absorbed onto the surface of cellulosic fibres, due to the cationic amino groups and the electrostatic interactions between chitosan and cellulose pulp. ${ }^{16}$ Chitosan in combination with polyvinyl alcohol and starch was studied by Mucha and Miskiewicz. They determined strong ionic interactions between the

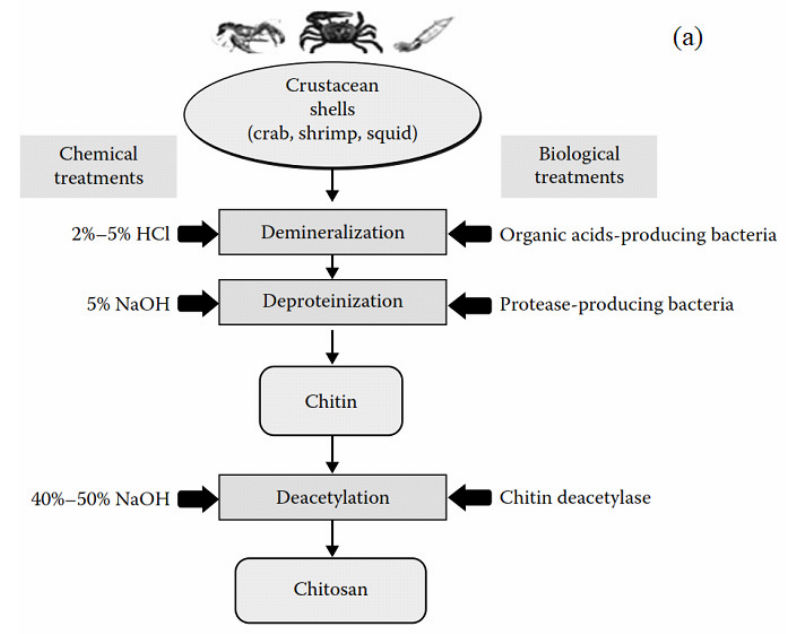

fillers and an increase in the paper tensile properties. ${ }^{17}$ Nada et al. found that the chitosan, cyanoethyl and carboxymethyl chitosan enhanced the strength properties of aged and un-aged paper sheets. ${ }^{18}$ Fernandes et al. studied the distribution of chitosan onto the paper sheets, using a fluorescent derivative. ${ }^{19}$ Their results have proven that chitosan and its modifications could be used as evidence to understand the deposition of chitosan onto paper.

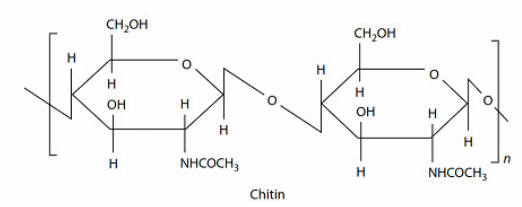

(b)

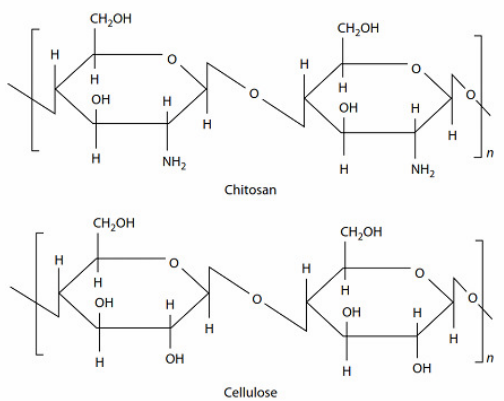

Figure 1: Chitin and chitosan production by chemical and biological treatments (a);

Chemical structure of chitin, chitosan and cellulose (b)

Generally, commercial chitosan has a 70-96\% degree of deacetylation, and its properties are often dependent on the residual N-acetyl-Dglucosamine groups. ${ }^{20-28}$ Chitosan and several of its innumerable derivatives can form thin membranous films to be used in packaging, ${ }^{29}$ encapsulation and drug delivery systems. ${ }^{30,31}$ Recently, several publications emerged on blending chitosan with different polymers, such as poly(vinyl alcohol), ${ }^{32,33}$ poly(N-vinyl pyrrolidone), ${ }^{34}$ polyvinylidene fluoride (PVDF), starch, ${ }^{36}$ cellulose and its derivatives ${ }^{37}$ etc.

In the production of paper, in order to impart hydrophobicity to the cellulose pulp, various sizing agents are used, such as rosin size and aluminium sulphate, as well as other synthetic sizing agents. These synthetic sizing agents can be replaced by some natural polymers, such a natural polymer can be chitosan.

In the literature, chitosan has been reported to be used as coating, ${ }^{10,38-44}$ or as a wet-end additive $^{24-28}$ in the papermaking process, to improve mechanical, barrier and optical properties of different paper types. Also, it could be used as a crosslinking agent, to enhance hydrogen bonding and thus increase paper strength. $^{38-44}$

From the considerations discussed above, the present work has been carried out in order to study the influence of chitosan addition in the composition of papers intended for documents and archives on their ageing stability. An increase in the strength and optical properties of the obtained papers over time was expected.

\section{EXPERIMENTAL}

\section{Materials}

Softwood pulp was delivered by SCA, Sweden, representing bleached sulphate kraft cellulose from pine and spruce trees, with the following specifications: breaking length of $3300 \mathrm{~m}$, acc. ISO 1924/2, tensile index of $26 \mathrm{~N} . \mathrm{m} / \mathrm{g}$ acc. ISO 1924-2, burst index of $1.5 \mathrm{kPa} \mathrm{m} / \mathrm{g}$ acc. ISO 2758 , tear index of $18.8 \mathrm{mN} . \mathrm{m}^{2} / \mathrm{g}$ acc. EN 21974 and $80 \%$ brightness acc. ISO 3088 .

Hardwood pulp - bleached hardwood kraft pulp from beech trees - was delivered by Svilosa AD, 
Bulgaria, and is available on the market under the registered trademark SVILOCELL®. Its properties were as follows: breaking length of $1900 \mathrm{~m}$, acc. ISO $1924 / 2$, tensile index of $18 \mathrm{~N} . \mathrm{m} / \mathrm{g}$ acc. ISO 1924-2, burst index of $0.75 \mathrm{kPa} \mathrm{m} / \mathrm{g}$ acc. ISO 2758, tear index of $2.3 \mathrm{mN} . \mathrm{m}^{2} / \mathrm{g}$ acc. EN 21974 and $80 \%$ brightness acc. ISO 3088 .

Chitosan, with the molecular weight lower than 30 $\mathrm{kDa}$ and deacetylation degree higher than $80 \%$, was purchased from Honeywell FlukaTM. A 5\% chitosan solution was prepared by dissolving chitosan in acetic acid. The solution was mixed for $10 \mathrm{~min}$ at $85^{\circ} \mathrm{C}$ and then cooled to room temperature.

The chitosan solution was added during the formation of the paper sheets in various amounts $0.2 \%, 1 \%$ and $2 \%$ o.d.f. Paper samples were made of different fibrous compositions from bleached sulphate softwood pulp (BSWP) and bleached sulphate hardwood pulp (BHWP), in different ratios, and were subjected to artificial thermal ageing at $105{ }^{\circ} \mathrm{C}$ for 24 hours.

\section{Methods}

\section{Preparation of paper samples}

The used kraft pulps were refined by a laboratory Jokro mill, with six refining units, acc. ISO 52643:21979. The refining consistency in each unit was $6 \%$ (16 g o.d.f. in $267 \mathrm{~mL}$ of water). The two pulps were refined separately. The Schopper Riegler Value (ISO 5267-1/AC:2004) of the bleached softwood pulp was $33^{\circ} \mathrm{SR}$ and that of the bleached hardwood pulp was 30 ${ }^{\circ} \mathrm{SR}$.

Paper suspensions, with a concentration of $2 \%$, were prepared, using 4 combinations of pulps, to be further used as a basis for the production of document paper:

1) $100 \%$ bleached sulphate softwood pulp;

2) $80 \%$ bleached sulphate softwood pulp: $20 \%$ bleached sulphate hardwood pulp;

3) $50 \%$ bleached sulphate softwood pulp: $50 \%$ bleached sulphate hardwood pulp;

4) $100 \%$ bleached sulphate hardwood pulp.

Then, chitosan $-0.2,1$ and $2 \%$ of o.d.f., rosin size - $3 \%$ of o.d.f. and $\mathrm{Al}_{2}\left(\mathrm{SO}_{4}\right)_{3}-4.5 \%$ of o.d.f. were added as additives. The aluminium sulphate and rosin size were used as wet-end additives with the purpose to determine their effect on the aging of the resulting paper samples, as these additives were widely used in papermaking in the past years to increase the hydrophobicity of paper for documents, charts and drawings, which may become conservation objects.

The composition of the obtained 12 paper types is presented in Table 1. The components were added in the same sequence as presented in Table 1, and the reaction time between the additives was in the range of 2-3 minutes. All paper samples were prepared on a laboratory paper machine (Rapid-Kothen, Germany) according to ISO 5269-2:2005, with a grammage of 70 $\mathrm{g} / \mathrm{m}^{2}$, and dried at $96^{\circ} \mathrm{C}$ for 7 minutes.

Table 1

Composition of paper samples and amounts of additives used

\begin{tabular}{|c|c|c|c|c|c|c|}
\hline $\begin{array}{c}\text { Paper } \\
\text { sample }\end{array}$ & Fibre composition & \multicolumn{3}{|c|}{$\begin{array}{l}\text { Chitosan, } \\
\% \text { of o.d.f. }\end{array}$} & $\begin{array}{l}\text { Rosin size, } \\
\% \text { of o.d.f. }\end{array}$ & $\begin{array}{l}\mathrm{Al}_{2}\left(\mathrm{SO}_{4}\right)_{3}, \\
\% \text { of o.d.f. }\end{array}$ \\
\hline 1. & $100 \%$ BSWP & \multicolumn{3}{|c|}{-} & - & - \\
\hline 2. & 80\% BSWP:20\% BHWP & \multicolumn{3}{|c|}{-} & - & - \\
\hline 3. & 50\% BSWP:50\% BHWP & \multicolumn{3}{|c|}{ - } & - & - \\
\hline 4. & $100 \%$ BHWP & \multicolumn{3}{|c|}{-} & - & - \\
\hline 5. & $100 \%$ BSWP & 0.2 & 1 & 2 & - & - \\
\hline 6. & 80\% BSWP:20\% BHWP & 0.2 & 1 & 2 & - & - \\
\hline 7. & 50\% BSWP:50\% BHWP & 0.2 & 1 & 2 & - & - \\
\hline 8. & $100 \%$ BHWP & 0.2 & 1 & 2 & - & - \\
\hline 9. & $100 \%$ BSWP & 0.2 & 1 & 2 & 3 & 4.5 \\
\hline 10. & $80 \%$ BSWP:20\% BHWP & 0.2 & 1 & 2 & 3 & 4.5 \\
\hline 11. & 50\% BSWP:50\% BHWP & 0.2 & 1 & 2 & 3 & 4.5 \\
\hline 12. & $100 \%$ BHWP & 0.2 & 1 & 2 & 3 & 4.5 \\
\hline
\end{tabular}

\section{Paper properties}

The tensile strength of the papers was determined as tensile index, $\mathrm{Nm} / \mathrm{g}$, on a Zwick/Roell tensile testing machine, according to ISO 1924-1/2:1999. Paper stripes of $18 \mathrm{~cm}$ in length and $1.5 \mathrm{~cm}$ in width were used and a minimum of ten probes for each sample was tested. The samples were analysed in the standard atmosphere at $23{ }^{\circ} \mathrm{C}$ and $50 \%$ relative humidity. The cross-speed head was $20 \mathrm{~mm} / \mathrm{min}$. The distance between the clamps was $10 \mathrm{~cm}$.
Bending resistance was measured according to standard ISO 5626:1993 - Paper - Determination of folding endurance. Folding endurance is the ability of the paper to withstand repeated bending of $180^{\circ}$ and is expressed by the number of double folds. The tests were performed on a Schopper apparatus, using strips with dimensions of $100 \times 15 \mathrm{~mm}$, stretched between the terminals with a force of $10 \mathrm{~N}$. After rupture, the counter of the device counts the number of double folds that the tape has withstood. The Schopper 
method is applicable to paper of thicknesses up to 0.25 $\mathrm{mm}$, and having a tensile strength greater than 1.33 $\mathrm{kN} / \mathrm{m}$.

Water absorptiveness was determined with the Cobb value, as described in the standard method ISO $535: 2014$, according to which the paper is placed in contact with a given amount $(100 \mathrm{~mL})$ of water for 45 seconds and weight differences are then compared. For each paper type, five sample tests were made.

Artificial thermal ageing was conducted according to ISO 5630-1:2014 at a temperature of $105{ }^{\circ} \mathrm{C}$, for 24 $\mathrm{h}$ in a chamber with constant air circulation. After each 6 hours, the whiteness CIE was measured.

The optical properties of the obtained paper samples were examined in terms of Whiteness CIE at D65_10 by a Konica Minolta Spectrophotometer CM3630 (Frank, PTI), according to ISO 11475:2004. For each sample, ten measurements were made at different locations on the surface.

Before the measurements, the samples were conditioned at $50 \% \mathrm{RH}$ and $23 \pm 2{ }^{\circ} \mathrm{C}$ for $72 \mathrm{~h}$.

\section{RESULTS AND DISCUSSION}

Investigation of strength properties and water absorption capacity

The tensile strength indicates the ability of paper to resist tension and elongation, as well as flexibility, both of which depend on the strength of fibres, bonding between them, fibre length and surface area. The difference in tensile strength among papers is mainly due to the difference in the fillers and their concentrations. The results of the tensile strength of the investigated paper samples expressed as tensile index (TI, Nm/g) are presented in Table 2.

From the data in the table, it is noticed that, at $100 \%$ bleached softwood pulp (BSWP) content, there are small differences among tensile index values of different paper types, as the additives enhance this parameter compared to the control sample (the sample with no additives), except for the samples with the largest amount of chitosan $2 \%$ of o.d.f., rosin size $-3 \%$ of o.d.f. and $\mathrm{Al}_{2}\left(\mathrm{SO}_{4}\right)_{3}-4.5 \%$ of o.d.f., where a decrease of about $4 \%$ is observed. This can be explained by the fact that higher amounts of additives impact negatively the inter-fibre bonding. The best results were obtained for the paper samples comprising $0.2 \%$ chitosan, showing an improvement in tensile index of about $10 \%$, compared to the control sample. The higher the amount of chitosan is, the more the tensile index decreases, but it still stays higher than that of the control paper sample. This might be caused by the increased number of positively charged groups from the chitosan molecule and probably insufficient amount of $\mathrm{OH}$-groups from the softwood fibres and their decreased ability to form H-bonds. With increasing the chitosan addition in the paper samples containing rosin size and $\mathrm{Al}_{2}\left(\mathrm{SO}_{4}\right)_{3}$ as additives, the tensile index of the papers decreased, compared to the samples comprising only chitosan, but still at $0.2 \%$ of o.d.f. and $1 \%$ of o.d.f. chitosan, there is a positive effect, with about $5-7 \%$ higher tensile index, compared to the control sample. It was concluded that the addition of $0.2 \%$ chitosan is sufficient for enhancing the tensile index of paper samples made from $100 \%$ BSWP with about $10 \%$, while an additional increase in the amount of chitosan above $1 \%$ has a negative effect.

The results for the pulp combination 80\%BSWP:20\%BHWP show that all combinations of additives increase the tensile index of the papers, compared to the control sample. While adding the smallest amount of chitosan $-0.2 \%$ as a single additive, and the combination of chitosan $(0.2 \%)$ with rosin size (3\%) and $\mathrm{Al}_{2}\left(\mathrm{SO}_{4}\right)_{3}(4.5 \%)$, the tensile index increased by about $10 \%$, while with the other two chitosan additions ( $1 \%$ and $2 \%$ of o.d.f.), an enhancement in the tensile index of $50 \%$ and $100 \%$, respectively, is observed. These results indicate that the wet-end additives contribute to significant inter-fibre bonding. The high tensile index is also due to the excellent and uniform paper structure explained by the presence of softwood pulp, characterised by a larger content of hemicelluloses, which exhibits increased hydration. By adding $0.2 \%$ chitosan to the paper furnish of $80 \% \mathrm{BSWP}: 20 \% \mathrm{BHWP}$, the tensile strength of the obtained paper samples is improved with about $10 \%$, while increasing the chitosan addition (1\% and $2 \%$ ), with rosin size and $\mathrm{Al}_{2}\left(\mathrm{SO}_{4}\right)_{3}$ or without them, increased the tensile index by $50 \%$ and $100 \%$, respectively.

The tensile index results for the second pulp combination of $50 \%$ BSWP and $50 \%$ BHWP are lower than those for the first one, but the trends observed regarding the effect of increasing amounts of the additives are the same. As expected, adding more hardwood pulp to the suspension caused a decrease in the tensile strength.

The addition of chitosan to $100 \%$ BHWP has almost no effect on the tensile index of the obtained paper samples, while the combination of chitosan, rosin size and aluminium sulphate has a negative effect. Obviously, the chitosan 


\section{DIMITRINA TODOROVA and VESKA LASHEVA}

preferably bonds with the hardwood cellulose fibre in the water suspension and the free $\mathrm{OH}$ - groups are blocked, resulting in weak inter-fibre bonding during the drying process.

Table 2

Tensile index $(\mathrm{Nm} / \mathrm{g})$ of the obtained paper samples

\begin{tabular}{|c|c|c|c|c|c|}
\hline \multirow{3}{*}{ Raw material } & \multirow{3}{*}{ Paper composition } & \multicolumn{4}{|c|}{ Tensile strength (tensile index, $\mathrm{Nm} / \mathrm{g}$ ) } \\
\hline & & \multicolumn{4}{|c|}{ Chitosan addition, \% } \\
\hline & & 0 & 0.2 & 1 & 2 \\
\hline \multirow{3}{*}{$100 \%$ BSWP } & Only pulp & 87.39 & & & \\
\hline & Pulp and chitosan & & 97.15 & 94.24 & 91.34 \\
\hline & $\begin{array}{l}\text { Pulp, chitosan, rosin } \\
\text { size and } \mathrm{Al}_{2}\left(\mathrm{SO}_{4}\right)_{3}\end{array}$ & & 95.00 & 91.28 & 83.81 \\
\hline \multirow{3}{*}{$\begin{array}{l}\text { 80\% BSWP: } \\
\text { 20\% BHWP }\end{array}$} & Only pulp & 57.62 & & & \\
\hline & Pulp and chitosan & & 64.05 & 86.51 & 115.38 \\
\hline & $\begin{array}{l}\text { Pulp, chitosan, rosin } \\
\text { size and } \mathrm{Al}_{2}\left(\mathrm{SO}_{4}\right)_{3}\end{array}$ & & 63.88 & 88.94 & 120.26 \\
\hline \multirow{3}{*}{$\begin{array}{l}\text { 50\% BSWP: } \\
50 \% \text { BHWP }\end{array}$} & Only pulp & 67.44 & & & \\
\hline & Pulp and chitosan & & 71.00 & 76.29 & 89.02 \\
\hline & $\begin{array}{l}\text { Pulp, chitosan, rosin } \\
\text { size and } \mathrm{Al}_{2}\left(\mathrm{SO}_{4}\right)_{3}\end{array}$ & & 69.49 & 81.11 & 88.04 \\
\hline \multirow{2}{*}{ 100\% BHWP } & $\begin{array}{c}\text { Only pulp } \\
\text { Pulp and chitosan }\end{array}$ & 69.10 & 68.75 & 69.53 & 70.95 \\
\hline & $\begin{array}{l}\text { Pulp, chitosan, rosin } \\
\text { size and } \mathrm{Al}_{2}\left(\mathrm{SO}_{4}\right)_{3}\end{array}$ & & 43.76 & 51.07 & 59.52 \\
\hline
\end{tabular}

Table 3

Double folds (number) of the obtained paper samples

\begin{tabular}{|c|c|c|c|c|c|}
\hline \multirow{3}{*}{ Raw material } & \multirow{3}{*}{ Paper composition } & \multirow{2}{*}{\multicolumn{4}{|c|}{$\begin{array}{l}\text { Folding endurance (double folds, number) } \\
\text { Chitosan addition, } \%\end{array}$}} \\
\hline & & & & & \\
\hline & & 0 & 0.2 & 1 & 2 \\
\hline \multirow{3}{*}{$100 \%$ BSWP } & Only pulp & 480 & & & \\
\hline & Pulp and chitosan & & 560 & 550 & 550 \\
\hline & $\begin{array}{l}\text { Pulp, chitosan, rosin } \\
\text { size and } \mathrm{Al}_{2}\left(\mathrm{SO}_{4}\right)_{3}\end{array}$ & & 460 & 460 & 478 \\
\hline \multirow{3}{*}{$\begin{array}{l}\text { 80\% BSWP: } \\
20 \% \text { BHWP }\end{array}$} & Only pulp & 340 & & & \\
\hline & Pulp and chitosan & & 445 & 445 & 446 \\
\hline & $\begin{array}{l}\text { Pulp, chitosan, rosin } \\
\text { size and } \mathrm{Al}_{2}\left(\mathrm{SO}_{4}\right)_{3}\end{array}$ & & 446 & 456 & 425 \\
\hline \multirow{3}{*}{$\begin{array}{l}\text { 50\% BSWP: } \\
50 \% \text { BHWP }\end{array}$} & Only pulp & 150 & & & \\
\hline & Pulp and chitosan & & 242 & 595 & 700 \\
\hline & $\begin{array}{l}\text { Pulp, chitosan, rosin } \\
\text { size and } \mathrm{Al}_{2}\left(\mathrm{SO}_{4}\right)_{3}\end{array}$ & & 183 & 308 & 461 \\
\hline \multirow{3}{*}{ 100\% BHWP } & Only pulp & 20 & & & \\
\hline & Pulp and chitosan & & 53 & 45 & 80 \\
\hline & $\begin{array}{l}\text { Pulp, chitosan, rosin } \\
\text { size and } \mathrm{Al}_{2}\left(\mathrm{SO}_{4}\right)_{3}\end{array}$ & & 45 & 40 & 50 \\
\hline
\end{tabular}

Measuring folding endurance or double fold is important for papers with low grammage and high flexibility, intended to be used in many end use applications, such as wrapping, printing, high speed mechanical handling etc. The results presented in Table 3 show a very good impact of chitosan on the number of double folds of paper samples prepared from $100 \%$ BSWP, while the combination of chitosan with other two wet-end additives decreases the folding endurance. Thus, all the additions used in this study - of $0.2 \%, 1 \%$ and $2 \%$ chitosan - have a positive effect on the number of double folds in $100 \%$ softwood pulp. With this fibrous composition, the value of the 
double folds increases by $14 \%$ when adding chitosan, compared to the control sample.

The addition of chitosan also has a favourable effect on the strength and flexibility of paper samples from 80\%BSWP:20\%BHWP. In this case, the amount of added chitosan is not important, as the results are almost the same for $0.2 \%, 1 \%$ and $2 \%$ chitosan addition. Therefore, the desired effect can be achieved by adding only $0.2 \%$ chitosan. The addition of sizing agents to the paper samples comprising chitosan did not affect the double fold index in this fibrous composition.

For 50\%BSWP:50\%BHWP, adding $0.2 \%$ chitosan increased the number of double folds, compared to the control sample. The best results were obtained with the addition of $2 \%$ chitosan, where the increase was about $78.6 \%$. With the addition of rosin size and aluminium sulphate, an increase in the double fold index, compared to the control sample, was also observed.

The results show that the addition of $0.2 \%, 1 \%$ and $2 \%$ chitosan increases the number of double folds of paper samples made from 100\%BHWP. This is due to the positive effect that chitosan has on the tensile strength and flexibility of hardwood cellulose fibres, which are shorter and thickwalled. The best results were found after the addition of $2 \%$ chitosan, when an increase of $75 \%$ in the number of double folds was observed, compared to the control sample.

The resistance to the penetration of water was measured by $\mathrm{Cobb}_{60}$ values, as explained in ISO 535. From the obtained results, the addition of chitosan decreased water absorptiveness, i.e. $\mathrm{Cobb}_{60}$ value, as seen in Table 4. Binding of chitosan to cellulose fibres impairs the water sorption capacity of the produced paper.

For $100 \% \mathrm{BSWP}$, as a result of the addition of $0.2 \%, 1 \%$ and $2 \%$ chitosan, water absorption decreased by $58.5 \%$, compared to the control sample without chitosan. This shows that in order to achieve these results, it is not necessary to add chitosan in larger quantities than $0.2 \%$. The presence of rosin size and aluminium sulphate in the paper samples further reduced the water absorption capacity of the paper.

For the 80\%BSWP:20\%BHWP formulation, the water absorption ability was largely influenced by the presence of chitosan in the paper samples. When $0.2 \%$ chitosan was added, $\mathrm{Cobb}_{60}$ values decreased by $23 \%$, compared to the control sample, without chitosan. The best results, however, were observed for the addition of $2 \%$ chitosan and the other additives - rosin size and aluminium sulphate. The sizing agents reduced water absorption by $85 \%$.

Table 4

Water absorptiveness $\left(\mathrm{Cobb}_{60}, \mathrm{~g} / \mathrm{m}^{2}\right)$ of obtained paper samples

\begin{tabular}{|c|c|c|c|c|c|}
\hline \multirow{3}{*}{ Raw material } & \multirow{3}{*}{ Paper composition } & \multicolumn{4}{|c|}{ Water absorptiveness $\left(\mathrm{Cobb}_{60}, \mathrm{~g} / \mathrm{m}^{2}\right)$} \\
\hline & & \multicolumn{4}{|c|}{ Chitosan addition, $\%$} \\
\hline & & 0 & 0.2 & 1 & 2 \\
\hline \multirow{3}{*}{$100 \%$ BSWP } & Only pulp & 120.21 & & & \\
\hline & Pulp and chitosan & & 50.04 & 50.17 & 50.03 \\
\hline & $\begin{array}{l}\text { Pulp, chitosan, rosin } \\
\text { size and } \mathrm{Al}_{2}\left(\mathrm{SO}_{4}\right)_{3}\end{array}$ & & 40.07 & 30.21 & 20.42 \\
\hline \multirow{3}{*}{$\begin{array}{l}80 \% \text { BSWP: } \\
20 \% \text { BHWP }\end{array}$} & Only pulp & 130.28 & & & \\
\hline & Pulp and chitosan & & 100.05 & 80.84 & 60.53 \\
\hline & $\begin{array}{l}\text { Pulp, chitosan, rosin } \\
\text { size and } \mathrm{Al}_{2}\left(\mathrm{SO}_{4}\right)_{3}\end{array}$ & & 23.45 & 20.23 & 20.12 \\
\hline \multirow{3}{*}{$\begin{array}{l}50 \% \text { BSWP: } \\
50 \% \text { BHWP }\end{array}$} & Only pulp & 160.11 & & & \\
\hline & Pulp and chitosan & & 152.82 & 120.43 & 80.34 \\
\hline & $\begin{array}{l}\text { Pulp, chitosan, rosin } \\
\text { size and } \mathrm{Al}_{2}\left(\mathrm{SO}_{4}\right)_{3}\end{array}$ & & 140.23 & 105.49 & 50.27 \\
\hline \multirow{3}{*}{$100 \%$ BHWP } & Only pulp & 150.04 & & & \\
\hline & Pulp and chitosan & & 100.85 & 70.86 & 50.04 \\
\hline & $\begin{array}{l}\text { Pulp, chitosan, rosin } \\
\text { size and } \mathrm{Al}_{2}\left(\mathrm{SO}_{4}\right)_{3}\end{array}$ & & 20.32 & 20.17 & 20.11 \\
\hline
\end{tabular}

For the 50\%BSWP:50\%BHWP pulp combination, the addition of chitosan was observed to have a moderate effect on water absorption, causing a decrease in the water 
absorption values, especially with increasing chitosan addition, compared to the control sample. It should be noted that the combined effect of chitosan, rosin size and aluminium sulphate in limiting the water absorptiveness of paper was much more significant.

The addition of chitosan to 100\%BHWP significantly reduced the water absorption capacity of the $100 \%$ hardwood cellulose paper samples, compared to the control sample. With the addition of $0.2 \%$ chitosan, the water absorption decreased by $34 \%$, while the best results were obtained after the addition of $2 \%$ chitosan, which led to a decrease of $67 \%$. The addition of sizing agents further reduced the water absorption capacity of paper samples by $86.7 \%$.

\section{Investigation of ageing stability}

The accelerated aging tests in this work were carried out for three major purposes. The first was to establish in a conveniently short time the relative ranking of the paper materials, with respect to their chemical stability or physical durability. The second was to estimate or "predict" the potential long-term serviceability of the prepared papers under expected conditions of use. Thirdly, accelerated aging allows speeding up the process of deterioration under laboratory conditions, in order to elucidate the chemical reactions involved (the "mechanism" of the degradation) and the physical consequences thereof.

The accelerated aging deals with the chemical stability or resistance of materials. The chemical changes occurring during aging are ultimately responsible for the physical disintegration and failure of materials. A typical external sign of aging in paper is a decrease in the degree of whiteness and deterioration of physical and mechanical properties of the paper. The result of paper aging is primarily associated with the presence of carbonyl groups, formed as a result of oxidation of the hydroxyl groups in the second and third carbon atoms in the elementary unit of the macromolecule of cellulose and the presence of both aldehyde and carboxyl groups in the cellulose materials. The reduction of the whiteness degree of paper is mainly related to the presence of lignin and hemicelluloses in the pulp composition; but also to the presence of metal ions and the type of the sizing agent used. ${ }^{44}$

The investigation on the whiteness stability of the obtained paper samples during accelerated thermal ageing is shown in Figures 2 to 5. From the figures, it may be remarked that the ageing of paper samples with the addition of chitosan, as well as chitosan in combination with the sizing agents, have the same behaviour during the 24 hours of accelerated ageing, except for the raw material combination of 50\%BSWP:50\%BHWP. The largest decrease in whiteness is observed in the first 6 hours of thermal ageing, which, in most cases, steadily continued until the end of the 24 hours. At the end of the thermal ageing process, the whiteness degree decreased by approximately $7 \%$ for all the samples.

Comparing the results in Figure 2 and Figure 3 , it could be concluded that replacing $20 \%$ of softwood with hardwood pulp does not have a significant effect on the whiteness degree of paper samples, in the presence of the additives investigated in this work, when considering both its initial value and after 24 hours of accelerated thermal ageing.

The most drastic changes in whiteness are observed in the fibrous material made from 50:50 coniferous and deciduous pulps (Fig. 4), which is probably explained by the multicomponent composition of the paper samples and the fact that whiteness largely depends on the optical homogeneity of the studied materials. Therefore, paper samples made from homogeneous fibrous material have approximately the same whiteness values and identical aging curves.

For the paper samples prepared from the pulp combination of 50\%BSWP:50\%BHWP, with the addition of chitosan a clear dependence is observed (see the interrupted curves in Fig. 4). With increasing the amount of chitosan in the composition, paper whiteness remains more stable over time - as the addition of chitosan rises from 0.2 to $2 \%$, the curves shift to the right, which indicates increased colour stability up to 12 hours, with a decrease in whiteness by only about $6 \%$. Generally, higher whiteness values and more stable aging behaviour are observed for the $2 \%$ addition of chitosan (the curves with round markers). This is especially valid up for a thermal aging period of up to 12 hours. However, in the paper prepared from $100 \%$ hardwood pulp, the lowest amount of chitosan $(0.2 \%)$ is sufficient for achieving good aging stability, in terms of reduced yellowing of the paper. As the quantity of softwood pulp in the composition increases, a higher amount of chitosan would be necessary for obtaining similar results. However, when considering the final whiteness of the paper samples after 24 hours of aging, according to the 
curves corresponding to the samples containing chitosan, rosin size and aluminium sulphate, in all four graphs, there is no significant difference in

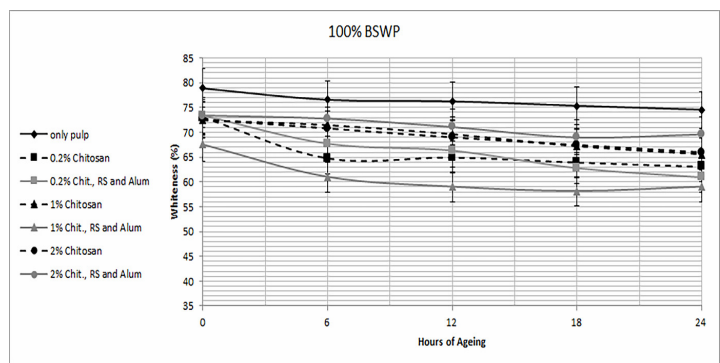

Figure 2: Dependence of paper whiteness on the duration of thermal aging for 100\%BSWP with and without chitosan

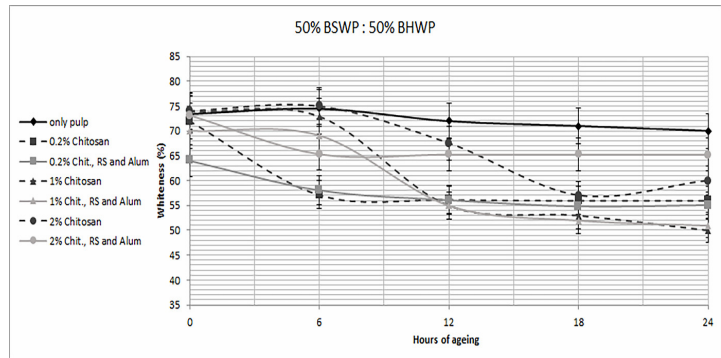

Figure 4: Dependence of paper whiteness on the duration of thermal aging for 50\%BSWP:50\%BHWP with and without chitosan

Thus, the whiteness of the paper samples containing the maximum amount of chitosan used $(2 \%)$, rosin size and aluminium sulphate differs very little from that of the sample containing the same amount of chitosan, in the absence of rosin size and aluminium sulphate. The effect is enhanced with increasing the content of hardwood pulp in the composition of the paper samples. These positive results are probably due to an improved charge balance in the paper suspension in the presence of chitosan (due to enough positively and negatively charged active groups from the wet-end chemical additives) and enhanced microstructure of the paper, due to the formed ionic, hydrogen bonds and van der Waals interactions. Hence, the addition of chitosan only in the composition of paper would be sufficient for forming paper that would not necessitate special storage conditions in libraries or specific separation of individual types of paper.

In addition to the well-known visual sign of paper aging, namely its yellowing or discoloration, the main functional properties of paper that change over time are its mechanical properties, such as the tensile strength and folding the behaviour of the samples, compared to the paper formulations without sizing agents.

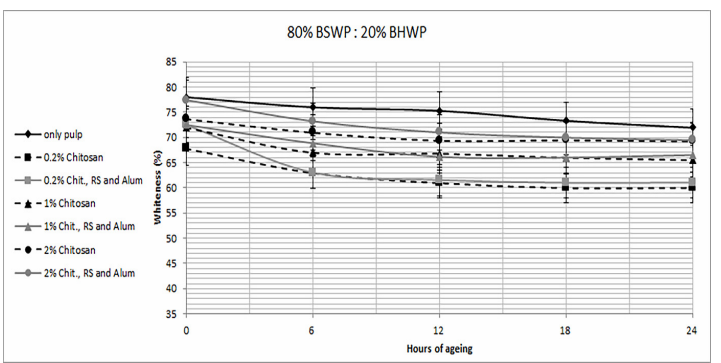

Figure 3: Dependence of paper whiteness on the duration of thermal aging for 80\%BSWP:20\%BHWP with and without chitosan

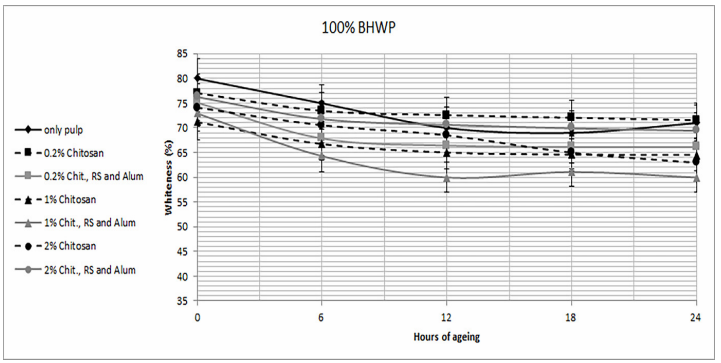

Figure 5: Dependence of paper whiteness on the duration of thermal aging for $100 \%$ BHWP with and without chitosan

endurance. Folding endurance is expressed as the number of double folds (DF, number), and represents the ability of paper to withstand repeated bending of $180^{\circ}$. It depends mainly on the length of the fibres itself, on their flexibility and strength, and less on the bonding forces between them. Nevertheless, biopolymers, such as chitosan, improve the fibre interactions and despite the anisotropy of the paper, improve spatial homogeneity. Therefore, for the tested paper samples, an improvement in the resistance to bending should be expected, with an increasing amount of biopolymer, and after the process of thermal aging. Chitosan in the paper composition forms ionic bonds, due to its $\mathrm{OH}$ groups and amino groups, with hemicelluloses and cellulose, thus leading to enhanced physical properties of paper.

The evolution of folding endurance during thermal aging is different depending on the type of fibrous material used to form the paper. A general observation of Figures 6 to 9 reveals that, in the paper samples with higher content of softwood pulp, this parameter decreases by approximately $50 \%$ after 15 hours of thermal 
aging, while in the samples with predominantly hardwood fibrous material, the same decrease is observed after only 6 hours of accelerated thermal aging.

A comparative analysis of the results presented for the double folds of the paper samples containing different additives (Fig. 6 to Fig. 9), before and after 24 hours of thermal

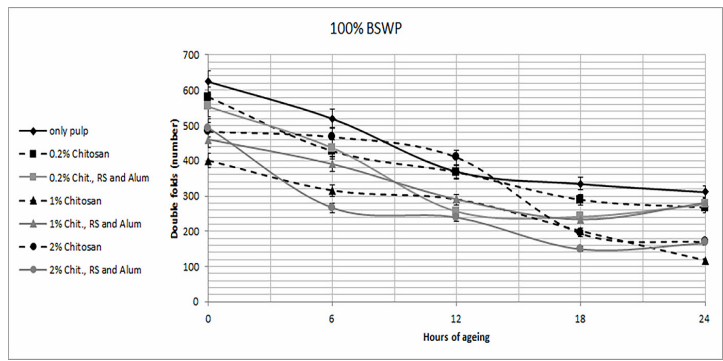

Figure 6: Dependence of paper double folds on the duration of thermal aging for $100 \%$ BSWP with and without chitosan

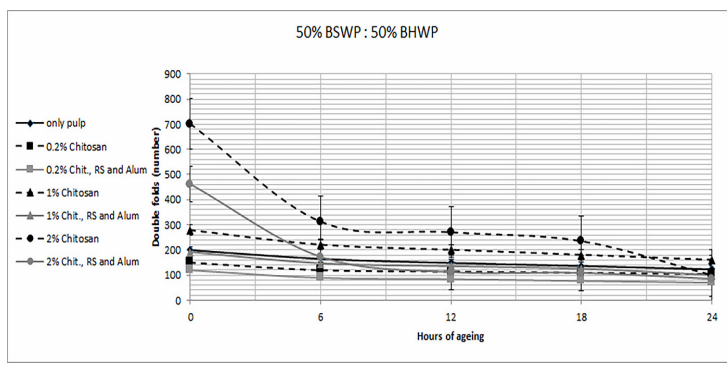

Figure 8: Dependence of paper double folds on the duration of thermal aging for 50\%BSWP:50\%BHWP with and without chitosan

In the case of the 100\%BSWP sample (Fig. 6), the addition of $0.2 \%$ chitosan, both with and without rosin size and aluminium sulphate (the curves with square markers), is sufficient for insuring a high number of double folds, both before and after the paper undergoes thermal ageing, though the value achieved is still lower than that of the sample made without any additives. Meanwhile, for 100\%BHWP (Fig. 9), all of the chemical additives have a positive effect on this parameter, compared to the control sample. Thus, before aging, an increase with 60 units is observed with the addition of $2 \%$ chitosan, followed by a rapid decrease after the first 6 hours of thermal ageing. This confirms the beneficial effect of chitosan on hardwood pulp, where it forms strong hydrogen bonding with the cellulose, but also with its high content of hemicelluloses. aging, confirms the positive effect of $2 \%$ chitosan addition (the curves with round markers) on the folding endurance of paper, due to its ability to form more hydrogen bonds, including with the amino groups, which is most clearly seen in the samples comprising more than $20 \%$ hardwood pulp.

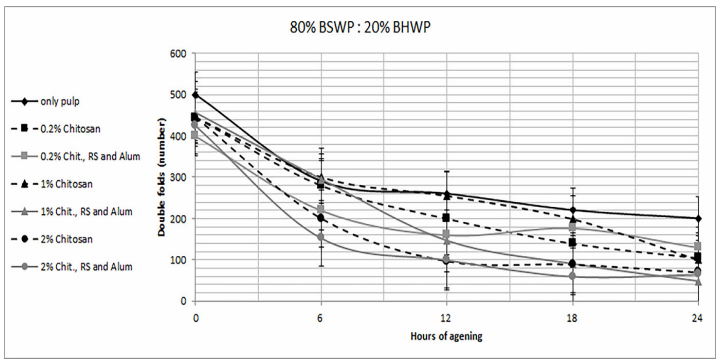

Figure 7: Dependence of paper double folds on the duration of thermal aging for $80 \%$ BSWP: $20 \%$ BHWP with and without chitosan

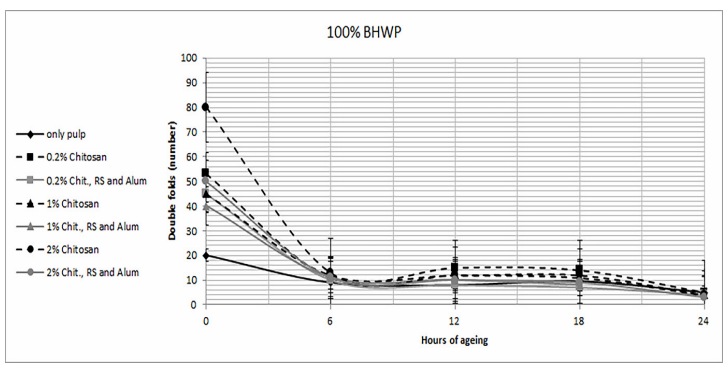

Figure 9: Dependence of paper double folds on the duration of thermal aging for $100 \%$ BHWP with and without chitosan

\section{CONCLUSION}

The present work confirmed the positive effect of chitosan addition during paper-making on the tensile strength, folding endurance and water absorption properties of paper sheets. Thus, $0.2 \%$ chitosan is sufficient for enhancing the tensile strength of paper samples made from $100 \%$ bleached softwood cellulose with about $10 \%$, while further increase of the amount of chitosan above $1 \%$ has a negative effect. In the case of the paper furnish from $80 \%$ bleached softwood pulp and $20 \%$ bleached hardwood pulp, the addition of $0.2 \%$ chitosan improved the tensile strength of the paper samples with about $10 \%$, but increasing the chitosan addition to $1 \%$ and $2 \%$, with or without rosin size and $\mathrm{Al}_{2}\left(\mathrm{SO}_{4}\right)_{3}$, increases the tensile index by $50 \%$ and $100 \%$, respectively. The best strength properties were obtained for the samples prepared from $80 \%$ bleached softwood and $20 \%$ 
bleached hardwood pulp, with the maximum addition of chitosan $-2 \%$, and with $3 \%$ rosin size, along with $4.5 \% \mathrm{Al}_{2}(\mathrm{SO} 4)_{3}$.

Water absorptiveness studies have revealed that the addition of chitosan to the paper furnish reduces the hydrophilicity of paper sheets. The best results were obtained for paper samples prepared from $100 \%$ bleached softwood pulp, where the addition of $0.2 \%$ chitosan was sufficient to impart hydrophobicity. The addition of rosin size and $\mathrm{Al}_{2}(\mathrm{SO} 4)_{3}$ to the paper samples after the addition of $2 \%$ chitosan decreased twofold the water absorption capacity of the paper.

Paper yellowing during thermal aging could be reduced by adding a certain amount of chitosan to the paper furnish, for instance, in the paper made of $100 \%$ hardwood pulp, $0.2 \%$ chitosan is sufficient to maintain an acceptable paper whiteness. As the amount of coniferous pulp increases in the paper furnish, it is necessary to raise the addition of chitosan as well. Otherwise said, in the papermaking process, adding chitosan to combined paper furnish from coniferous and deciduous pulps would allow achieving higher resistance to yellowing in paper sheets.

Paper samples containing higher content of softwood pulp have a lower number of double folds by approximately $50 \%$ after 15 hours of thermal aging, while those made from predominantly hardwood fibrous material, the same decrease is observed after 6 hours of accelerated thermal aging.

The study demonstrated that chitosan can be used in the production of all kraft document papers, which normally contain aluminium sulphate, as the interaction of the additives has no negative effects on the properties of the paper. Also, it can be summarized that, of the additive amounts and fibrous compositions studied here, the most effective appears to be the addition of $1 \%$ chitosan to the paper furnish of $50 \%$ bleached softwood pulp and $50 \%$ bleached hardwood pulp. Therefore, manufacturing document paper using this combination would be a convenient procedure, allowing to obtain paper sheets with enhanced paper properties, even over time.

ACKNOWLEDGMENT: Authors gratefully acknowledge the financial support of the Scientific Research Fund - Bulgaria, under project "Investigation of new posibilities for obtaining multifunctional properties of paper", No 920 (КП-06-H49/1).

\section{REFERENCES}

1 J. Blechschmidt, S. Heinemann, H.-J. Putz, M. Laufmann et al., in "Handbook of paper and board", edited by H. Holik, Wiley-VCH Verlag GmbH\&Co. KgaA, Weinheim, 2006, pp. 20-61.

2 M. Milichovsky, B. Česek and J. Gojny, Cellulose Chem. Technol., 49, $853 \quad$ (2015), https://www.cellulosechemtechnol.ro/pdf/CCT910(2015)/p.853-862.pdf

3 J. Tintner, F. Reitner, E. Smidt and B. Hinterstoisser, Cellulose Chem. Technol., 52, 105 (2018), https://www.cellulosechemtechnol.ro/pdf/CCT12(2018)/p.105-111.pdf

4 L. Zatoka, N. Balianytsia, S. Mozhova, A. Subbota et al., Manuscript and book heritage of Ukraine, 20 488, https://doi.org/10.15407/rksu.20.488

5 C. Shahani, in Procs. ASTM/ISR Workshop on the Effects of Aging on Printing and Writing Papers, Philadelphia, July, 1994, pp.1-18, https://www.loc.gov/preservation/resources/rt/Accelera tedAging.pdf

6 M.C. Area and H. Cheradame, BioResources, 6, 5307 (2011), https://bioresources.cnr.ncsu.edu/BioRes_06/BioRes_0 6_4_5307_Area_Cheradame_Paper_Aging_Degrad_R eview_2177.pdf

7 V.K. Rastogi and P. Samyn, Coatings, 5, 887 (2015), https://doi.org/10.3390/coatings5040887

W. Zhang, H. Xiao and L. Qian, Carbohyd. Polym., 101, 401 (2014), doi: 10.1016/j.carbpol.2013.09.097

9 N. Bordenave, S. Grelier and V. Coma, Biomacromolecules, 11, 88 (2010), doi: 10.1021/bm9009528

10 U. V. Brodnjak, Progress in Organic Coatings, 112, 86 (2017), doi: 10.1016/j.porgcoat.2017.06.030

11 W.M. Bruck, J.W. Slater and B.F. Carney in "Chitin, chitosan, oligosaccharides and their derivatives: biological activities and applications", edited by Se-Kwon Kim, Taylor and Francis Group, LLC, ISBN 978-1-4398-1603-5, 2011, pp. 11-23, https://doi.org/10.1201/EBK1439816035

12 H. Kjellgren, M. Gällstedt, G. Engström and L. Järnström, Carbohyd. Polym, 6, 453 (2006), https://doi.org/10.1016/j.carbpol.2006.02.005

13 U.V. Brodnjak and K. Tihole, Coatings, 10, 497 (2020), https://doi.org/10.3390/coatings10050497

14 M. Gällstedt and M.S. Hedenqvist, Carbohyd. $\begin{array}{llll}\text { Polym., } & 63, & 46 & \text { (2006), }\end{array}$ https://doi.org/10.1016/j.carbpol.2005.07.024

15 M. Laleg and I. I. Pikulik, Nord Pulp Pap. Res., 7, 174 (1992), https://doi.org/10.3183/npprj-1992-07-04p174-180

16 H. Li, Y. Du and Y. Xu, J. Appl. Polym. Sci., 91, 2642 (2004), https://doi.org/10.1002/app.13444

17 M. Mucha and D. Miśkiewicz, J. Appl. Polym. Sci., 77, 3210 (2000), https://doi.org/10.1002/10974628(20000929)77:14<3210::AID-APP230>3.0.CO;27 
18 A.M.A. Nada, M. El-Sakhawy, S. Kamel, M.A.M Eid el al., Carbohyd. Polym., 63, 113 (2006), https://doi.org/10.1016/j.carbpol.2005.08.028

19 S.C.M. Fernandes, C.S.R. Freire, A.J.D. Silvestre, C.P. Neto et al., Carbohyd. Polym., 78, 760 (2009), https://doi.org/10.1016/j.carbpol.2009.06.012

${ }^{20}$ C.K.S. Pillai, W. Paul and C.P. Sharma, Prog. Polym. Sci., 34, 641 (2009), doi:10.1016/j.progpolymsci.2009.04.001.

${ }^{21} \mathrm{P}$. Wu and Z. Liu, Cellulose Chem. Technol., 51, 521

https://www.cellulosechemtechnol.ro/pdf/CCT56(2017)/p.521-528.pdf

22 M. Popa, B. C. Ciobanu, L. Ochiuz, J. Desbriers, et al., Cellulose Chem. Technol., 52, 353 (2018), https://www.cellulosechemtechnol.ro/pdf/CCT56(2018)/p.\%20353-370.pdf

23 A. Salama, Cellulose Chem. Technol., 52, 903 (2018),

https://www.cellulosechemtechnol.ro/pdf/CCT910(2018)/p.903-907.pdf

24 M. Wu, W. Lv, F. Wang, Z. Long, et al., Cellulose Chem. Technol., 52, $43 \quad$ (2018), https://www.cellulosechemtechnol.ro/pdf/CCT12(2018)/p.43-49.pdf

25 L. Vikele, M. Laka, I. Sable, L. Rozenberga, et al., Cellulose Chem. Technol., 51, 67 (2017), https://www.cellulosechemtechnol.ro/pdf/CCT12(2017)/p.67-73.pdf

26 L.F. Zemljic, J.V. ValhALH and T. Kreze, Cellulose Chem. Technol., 51, 75 (2017), https://www.cellulosechemtechnol.ro/pdf/CCT12(2017)/p.75-81.pdf

27 M. Rohi, O. Ramezani, M. Rahmanina, S. M. Zabihzadeh, et.al., Cellulose Chem. Technol., 50, 873 (2016),

https://www.cellulosechemtechnol.ro/pdf/CCT78(2016)/p.873-878.pdf

28 L. Andze, J. Zoldners, L. Rozenberga, I. Sable, et al., Cellulose Chem. Technol., 52, 873 (2018), https://www.cellulosechemtechnol.ro/pdf/CCT910(2018)/p.873-881.pdf

29 P.C. Srinivasa, M.N. Ramesh, K.R. Kumar and R.N. Tharanathan, J. Food Eng., 63, 79 (2004), https://doi.org/10.1016/S0260-8774(03)00285-1

30 A. Salama and M. El-Sakhawy, Carbohyd. Polym., 113 500

(2014), https://doi.org/10.1016/j.carbpol.2014.07.022

31 S.P. Noel, H.S. Courtney, J.D. Bumgardner and W.O. Haggard, Clin. Orthop. Relat. Res., 468, 2074 (2010), https://doi.org/10.1007/s11999-010-1324-6

32 M. Mucha and A. Pawlak, Thermochim. Acta., 427, 69 (2005), https://doi.org/10.1016/j.tca.2004.08.014

33 A. Pawlak and M. Mucha, Thermochim. Acta., 396, $153 \quad$ (2003), https://doi.org/10.1016/S00406031(02)00523-3

34 K. Sakurai, Polymer, 41, 7051 (2000), https://doi.org/10.1016/S0032-3861(00)00067-7
35 R.D.S. Hussain and A.K. Pal, Cellulose Chem. Technol., $\quad 54, \quad 777 \quad$ (2020), https://doi.org/10.35812/CelluloseChemTechnol.2020. 54.77

36 Y.X. Xu, K.M. Kim, M.A. Hanna and D. Nag, Ind. Crops Prod., $21, \quad 185 \quad$ (2005), https://doi.org/10.1016/j.indcrop.2004.03.002

37 Y.B. Wu, S.H. Yu, F.L. Mi, C.W. Wu, et al., Carbohyd. Polym., 57, $435 \quad$ (2004), https://doi.org/10.1016/j.carbpol.2004.05.013

38 J. Kuusipalo, M. Kaunisto, A. Laine and M. Kellomäki, TAPPI J., 4, $17 \quad$ (2005), https://www.researchgate.net/publication/279715893_

Chitosan_as_a_coating_additive_in_paper_and_paperb oard

39 H. Kjellgreen, in "Barrier of greaseproof paper", Karlstadt University, Faculty of Technology and Science, Sweden, 2005, pp. 1-94, www.divaportal.org/smash/get/diva2:5289/FULLTEXT01.pdf

40 A.B. Reis, C.M.P. Yoshida, E.S.D. Vilela, R.S. Nascimento et al., Journal of Research updates in Polymer Science, 2, $122 \quad$ (2013), https://doi.org/10.6000/1929-5995.2013.02.02.6

${ }^{41}$ T Akter, J. Nayeem, A.Hai Quadery, M.A. Razzaq, et al., Cellulose Chem. Technol., 54, 95 (2020), https://doi.org/10.35812/CelluloseChemTechnol.2020. 54.11

${ }^{42}$ J. Atkinson, A. Mondala, Y.D.S. Senger, R. AlMubarak, et al. , Cellulose Chem. Technol., 51, 477 (2017), https://www.cellulosechemtechnol.ro/pdf/CCT56(2017)/p.477-481.pdf

43 E. Bobu, R. Nicu, P. Obrocea, E. Ardelean, et al., Cellulose Chem. Technol., 50, 689 (2016), https://www.cellulosechemtechnol.ro/pdf/CCT56(2016)/p.689-699.pdf

44 R.L. Feller, in "Accelerated aging: Photochemical and Thermal Aspects", edited by D. Berland, Marina del Rey, CA: Getty Conservation Institute, 1994, pp. 37-43. 